\title{
Promoter Polymorphism (rs12770170, -184C/T) of Microseminoprotein, Beta as a Risk Factor for Benign Prostatic Hyperplasia in Korean Population
}

\author{
Ju Yeon Ban, Koo Han Yoo ${ }^{1}$ \\ Department of Dental Pharmacology, Dankook University School of Dentistry, Cheonan; \\ ${ }^{1}$ Department of Urology, Kyung Hee University School of Medicine, Seoul, Korea
}

Purpose: Benign prostatic hyperplasia (BPH) is the most common prostate disease in aging men. Microseminoprotein-beta (MSMB) is abundant in semen. In this study, we investigated association between single nucleotide polymorphisms (SNPs) at the promoter of the $M S M B$ gene and the risk for developing BPH in a Korean population.

Methods: We genotyped two promoter polymorphisms (rs12770171, -184C/T and rs10993994, -2C/T) of the MSMB gene by direct sequencing. Ninety-five BPH patients and 78 control subjects were recruited for this study. SNPStats and Haploview version 4.2 were used for genetic analyses. Multiple logistic regression models (codominant, dominant, recessive, and log-additive models) were applied to determine the odds ratio (OR), 95\% confidence interval (CI), and P-value.

Results: Genotype frequency of the rs12770171 SNP showed significant difference between BPH patients and controls (OR, 2.14; 95\% CI, 1.07-4.27; P =0.032 in the codominant 1 model; OR, 2.31; 95\% CI, 1.19-4.47; P =0.011 in the dominant model; and OR, 2.05; 95\% CI, 1.17-3.61; $\mathrm{P}=0.009$ in the log-additive model). Moreover, the SNP also showed association between the two groups (OR, 2.05; 95\% CI, 1.19-3.52; P=0.009). The rs10993994 SNP was not associated with BPH. In haplotype analysis, $\mathrm{CC}$ and TT haplotypes were associated with $\mathrm{BPH}(\mathrm{P}<0.05)$.

Conclusions: This result indicates that a promoter polymorphism (rs12770170, -184C/T) in the MSMB gene may be associated with $\mathrm{BPH}$ development in a Korean population.

Keywords: Prostatic hyperplasia; Single nucleotide polymorphism; Beta-microseminoprotein

\section{INTRODUCTION}

Benign prostatic hyperplasia (BPH) is a common prostate disease in aging men [1]. Prevalence of $\mathrm{BPH}$ is $>50 \%$ in 60 -yearold men, and it is found in nearly all men more than 80 years of age [2]. BPH results in obstruction in urinary flow and produces lower urinary tract symptoms. Until now, the etiology of $\mathrm{BPH}$ is unknown. In order to diagnosis $\mathrm{BPH}$, prostate specific antigen (PSA) marker is used. However, it can be used as an assistant marker to predict BPH development [3].

Some previous studies showed that the family history of BPH and genetic polymorphisms are risk factors associated with an early age of onset of BPH [4-6]. Recently, several researchers reported a genetic association between $\mathrm{BPH}$ development and polymorphisms of specific genes including the vitamin $\mathrm{D}$ (1,25-dihydroxyvitamin D3) receptor (VDR) (FokI, BsmI, ApaI, and TaqaI loci), aldehyde dehydrogenase 2 (ALDH2), and nitric oxide synthase 2 (NOS2) genes [7-9].

Microseminoprotein-beta (MSMB) is the second most abundant protein in semen after PSA [10,11]. MSMB is a cysteinerich, $16-\mathrm{kDa}$ protein containing 94 amino acids. It is also known as prostate secretory protein of 94 amino acids (PSP94) and
Corresponding author: Koo Han Yoo

Department of Urology, Kyung Hee University Hospital at Gangdong, Kyung

Hee University School of Medicine, 892 Dongnam-ro, Gangdong-gu,

Seoul 134-727, Korea

Tel: +82-2-440-6271 / Fax: +82-2-440-7747 / E-mail: yookoohan@khu.ac.kr

Submitted: May 24, 2014 / Accepted after revision: June 14, 2014
This is an Open Access article distributed under the terms of the Creative Commons Attribution Non-Commercial License (http://creativecommons.org/licenses/by-nc/3.0/) which permits unrestricted non-commercial use, distribution, and reproduction in any medium, provided the original work is properly cited. 
$\beta$-inhibin [11-13]. The major biological function of MSMB is to inhibit the activity/secretion of the follicle stimulating hormone [13-15]. MSMB expression is observed in various zones of the prostate [16]. Whitaker et al. [13] reported that MSMB expression is high in normal and benign prostate tissue and is low or absent in prostate cancer tissues. Therefore, they suggested that MSMB might be a useful biomarker to diagnose prostate cancer, and that its serum levels may be useful as a prognostic marker [13].

In this study, we investigated whether two promoter polymorphisms (rs12770171, -184C/T and rs10993994, -2C/T) of the MSMB gene were associated with the BPH development in a Korean population.

\section{MATERIALS AND METHODS}

\section{Study Subjects}

We recruited 173 patients for this study. Patients who visited the Kyung Hee University Medical Center between January 2002 and December 2008 for treatment of lower urinary tract symptoms were selected. The clinical symptoms of the patients were evaluated according to the International Prostate Symptom Score, and the prostate volume of all patients was determined using transrectal ultrasonography (TRUS).

The levels of PSA in the sera of the patients was tested. The patients with a serum PSA level $>4 \mathrm{ng} / \mathrm{mL}$ were further tested by transrectal ultrasound-guided prostate biopsy to rule out prostate cancer. Prostate size was assessed by TRUS. Patients with prostate cancer, neurogenic bladder, urethral stricture, acute/chronic prostatitis, urinary tract infection, uncontrolled diabetes mellitus, hypertension, or those who had undergone previous pelvic surgery were excluded from this study.

We divided the patients into the $\mathrm{BPH}$ and control groups according to the diagnosis of BPH (control group, prostate vol-

Table 1. Clinical data of participants included in the study

\begin{tabular}{lcc}
\hline Variable & $\mathrm{BPH}(\mathrm{n}=95)$ & Control $(\mathrm{n}=78)$ \\
\hline Age $(\mathrm{yr})$ & $67.19 \pm 8.08$ & $63.19 \pm 10.23$ \\
Prostate volume $(\mathrm{mL})$ & $52.79 \pm 21.09$ & $22.50 \pm 5.29$ \\
IPSS & $18.36 \pm 7.40$ & $15.27 \pm 8.10$ \\
Serum PSA $(\mathrm{ng} / \mathrm{mL})$ & $6.48 \pm 6.00$ & $2.16 \pm 2.27$ \\
\hline
\end{tabular}

Values are presented as mean \pm standard deviation.

IPSS, International Prostate Symptom Score; BPH, benign prostatic hyperplasia; PSA, prostate-specific antigen. ume $<30 \mathrm{~mL}$; BPH group, prostate volume $>30 \mathrm{~mL}$ ). The demographic characteristics of the $\mathrm{BPH}$ and control groups are shown in Table 1 . The numbers of patients in the BPH and control groups were 95 and 78 , respectively.

All patients provided informed consent for use of their samples and clinical data. The Institutional Review Board at Kyung Hee University Medical Center approved the methods used in this study.

\section{SNP Selection and Genotyping}

To select promoter SNPs of the MSMB gene, we searched SNPs on the promoter region of the $M S M B$ gene in the SNP database (http://www.ncbi.nlm.nih.gov/SNP, BUILD 141). SNPs with $>0.1$ heterozygosity and $10 \%$ minor allele frequency were selected. Of these, we chose the two promoter polymorphisms rs12770171, $-184 \mathrm{C} / \mathrm{T}$ and rs10993994, -2C/T. The genotypes were determined by direct sequencing. Before sequencing, polymerase chain reaction (PCR) was conducted. Genomic DNA was amplified using the following primers: sense; $5^{\prime}$-CTG GTG GGC TGA CCT GTG GGC T-3' and antisense: 5'-GAT AAG CAG GAC TCC TTA TAG- $3^{\prime}$. PCR was performed for $39 \mathrm{cy}-$ cles at $94^{\circ} \mathrm{C}$ for 30 seconds, $59^{\circ} \mathrm{C}$ for 30 seconds, $72^{\circ} \mathrm{C}$ for 1 minute, and then at $1 \mathrm{cycle}$ at $72^{\circ} \mathrm{C}$ for 7 minutes to terminate the reaction. The PCR products were identified by electrophoresis on $1.8 \%$ agarose gel. The PCR products were sequenced using an ABI Prism 377 automatic sequencer (PE Applied Biosystems, Foster City, CA, USA). Sequence data were analyzed using SeqManII ver. 2.3 (DNASTAR Inc., Madison, WI, USA).

\section{Statistical Analysis}

For the analysis of genetic data, SNPStats (http://bioinfo.iconcologia.net/index.php) was used. The chi-square test was used to evaluate Hardy-Weinberg equilibrium of the two promoter SNPs. Next, the effect of SNPs was tested by multiple logistic regression models (codominant 1 , codominant 2, dominant, recessive, and log-additive) for odds ratio (OR), 95\% confidence interval (CI), and P-values; all the tests were run by adjusting for age as a covariable. A linkage disequilibrium (LD) block of SNPs in the MSMB gene was performed using Gabriel's algorithm in Haploview ver. 4.2 [17]. P-value significance was set at 0.05 .

\section{RESULTS}

Ninety-five BPH patients and 78 control subjects were genotyped in order to evaluate whether the two promoter polymor- 
phisms (rs12770171, -184C/T and rs10993994, -2C/T) of the $M S M B$ gene were associated with $\mathrm{BPH}$. The genotype distributions of the two promoter SNPs in this study were in HardyWeinberg equilibrium in the control subjects (rs12770171, $\mathrm{P}=$ 1.00; 10993994, $\mathrm{P}=0.65$, data not shown). Table 2 shows the genotype and allele distributions of two promoter SNPs in $\mathrm{BPH}$ patients and controls.

In allele distribution analysis, the T-allele frequency of rs12770171 was higher in the BPH group (27.1\%) than in the control group (15.4\%). This difference indicated that the polymorphism had a significant association with $\mathrm{BPH}(\mathrm{OR}, 2.05$; 95\% CI, 1.19-3.52; $\mathrm{P}=0.009$ ) (Table 2). The $\mathrm{C}$-allele frequency of rs10993994 was also higher in the BPH group (53.2\%) than in the control group (42.9\%). However, the rs10993994 allele did not show a significant association with $\mathrm{BPH}(\mathrm{P}=0.06)$.

Genotype analysis between the $\mathrm{BPH}$ and the control group was performed using logistic regression analysis with adjustment for age. There were significant differences between the $\mathrm{BPH}$ and control groups (rs12770171: OR, 2.14; 95\% CI, 1.074.27; $\mathrm{P}=0.032$ in the codominant 1 model [C/C vs. $\mathrm{C} / \mathrm{T}] ; \mathrm{OR}$, 2.31; 95\% CI, 1.19-4.47; $\mathrm{P}=0.011$ in the dominant model [C/C vs. $\mathrm{C} / \mathrm{T}+\mathrm{T} / \mathrm{T}]$; and $\mathrm{OR}, 2.05 ; 95 \% \mathrm{CI}, 1.17-3.61 ; \mathrm{P}=0.009$ in the log-additive model [C/C vs. C/T vs. T/T]) (Table 2).

Two SNPs (rs12770171, $-184 \mathrm{C} / \mathrm{T}$ and rs10993994, -2C/T) of the $M S M B$ gene were analyzed for $\mathrm{LD}$ and haplotypes using Haploview ver. 4.2. The LD block was composed of rs10993994 and $\operatorname{rs} 12770171\left(\mathrm{D}=1.00\right.$ and $\left.\mathrm{r}^{2}=0.287\right)$. There were three haplotypes in the LD block (haplotype CC, frequency $=0.51$; haplo-

Table 2. Genotype and allele frequencies of promoter polymorphisms MSMB gene in BPH patients and controls

\begin{tabular}{|c|c|c|c|c|c|c|}
\hline SNP & $\begin{array}{l}\text { Genotype/ } \\
\text { allele }\end{array}$ & $\mathrm{BPH}, \mathrm{n}(\%)$ & Control, n (\%) & Models & OR $(95 \% \mathrm{CI})$ & P-value \\
\hline \multirow[t]{7}{*}{ rs12770171, $-184 \mathrm{C} / \mathrm{T}$ promoter } & $\mathrm{C} / \mathrm{C}$ & $51(54.3)$ & $56(71.8)$ & Codominant 1 & $2.14(1.07-4.27)$ & 0.032 \\
\hline & $\mathrm{C} / \mathrm{T}$ & $35(37.2)$ & $20(25.6)$ & Codominant 2 & $3.76(0.75-18.78)$ & 0.110 \\
\hline & $\mathrm{T} / \mathrm{T}$ & $8(8.5)$ & $2(2.6)$ & Dominant & $2.31(1.19-4.47)$ & 0.011 \\
\hline & & & & Recessive & $2.96(0.60-14.57)$ & 0.150 \\
\hline & & & & Log-additive & $2.05(1.17-3.61)$ & 0.009 \\
\hline & $\mathrm{C}$ & $137(72.9)$ & $132(84.6)$ & & 1 & \\
\hline & $\mathrm{T}$ & $51(27.1)$ & $24(15.4)$ & & $2.05(1.19-3.52)$ & 0.009 \\
\hline \multirow[t]{7}{*}{ rs10993994, $-2 \mathrm{C} / \mathrm{T}$ promoter } & $\mathrm{C} / \mathrm{C}$ & $22(23.4)$ & $24(31.2)$ & Codominant 1 & $1.32(0.63-2.76)$ & 0.460 \\
\hline & $\mathrm{C} / \mathrm{T}$ & $44(46.8)$ & $40(51.9)$ & Codominant 2 & $2.29(0.94-5.58)$ & 0.070 \\
\hline & $\mathrm{T} / \mathrm{T}$ & $28(29.8)$ & $13(16.9)$ & Dominant & $1.57(0.79-3.16)$ & 0.200 \\
\hline & & & & Recessive & $1.92(0.90-4.08)$ & 0.090 \\
\hline & & & & Log-additive & $1.50(0.96-2.33)$ & 0.070 \\
\hline & $\mathrm{C}$ & $88(46.8)$ & $88(57.1)$ & & 1 & \\
\hline & $\mathrm{T}$ & $100(53.2)$ & $66(42.9)$ & & $1.52(0.99-2.33)$ & 0.060 \\
\hline
\end{tabular}

P-values were derived from logistic regression analyses with the codominant, dominant, recessive, and log-additive models.

MSMB, Microseminoprotein-beta; $\mathrm{BPH}$, benign prostatic hyperplasia; SNP, single nucleotide polymorphism; OR, odds ratio; CI, confidence interval. Missing genotype data are omitted.

Table 3. Haplotype analysis for association between the MSMB gene cluster polymorphisms and BPH

\begin{tabular}{|c|c|c|c|c|c|c|c|}
\hline \multirow{2}{*}{ Haplotype } & \multirow{2}{*}{ Frequency } & \multicolumn{2}{|c|}{$\mathrm{BPH}$} & \multicolumn{2}{|c|}{ Control } & \multirow{2}{*}{ Chi-square } & \multirow{2}{*}{ P-value } \\
\hline & & + & - & + & - & & \\
\hline $\mathrm{CC}$ & 0.51 & 88.0 & 102.0 & 89.3 & 66.7 & 4.10 & 0.043 \\
\hline TC & 0.27 & 51.0 & 139.0 & 42.7 & 113.3 & 0.01 & 0.910 \\
\hline $\mathrm{TT}$ & 0.22 & 51.0 & 139.0 & 24.0 & 132.0 & 6.62 & 0.010 \\
\hline
\end{tabular}

Haplotype consists of rs10993994 and rs12770171.

MSMB, Microseminoprotein-beta; BPH, benign prostatic hyperplasia; (+), ratio a specific haplotype of case or control; (-), ratio not a specific haplotype of case or control. 
type $\mathrm{TC}$, frequency $=0.27$; haplotype $\mathrm{TT}$, frequency $=0.22)(\mathrm{Ta}-$ ble 3). Haplotypes CC and TT were found to be associated with $\mathrm{BPH}$ (haplotype CC, chi-square $=4.10, \mathrm{P}=0.043$; haplotype TT, chi-square $=6.62, \mathrm{P}=0.010)($ Table 3$)$.

\section{DISCUSSION}

This is the first study to investigate the association between two promoter SNPs (rs12770171, -184C/T and rs10993994, -2C/T) and $\mathrm{BPH}$ development. Some previous studies have focused on the correlation between polymorphisms of the $M S M B$ gene and prostate cancer [18-20]. Although BPH is not directly linked to prostate cancer, epidemiological studies suggest that patients with BPH have an increased risk of prostate cancer [21]. Therefore, some biomarkers of prostate cancer are thought to be associated with $\mathrm{BPH}$ development.

In a genome-wide association study (GWAS), Thomas et al. $[22,23]$ found that the rs10993994 SNP of the MSMB gene was significantly associated with development of prostate cancer. The SNP rs10993994 (-59C/T) is located in the proximal promoter region (-59 bp) of the MSMB gene. This gene encodes for the prostatic secretory PSP94 protein, which is one of the major proteins secreted by the human prostate gland [10]. Recently, it was reported that the total PSP94 protein level in serum could be used to predict prostate cancer [24].

We analyzed the effect of the SNPs of the MSMB gene on $\mathrm{BPH}$ development. We also investigated the association of the haplotypes of the SNPs with susceptibility to BPH. We observed a significant association between the promoter polymorphism rs12770171 SNP (-184C/T) of the MSMB gene and BPH development, while the rs10993994 SNP did not show any significant association with $\mathrm{BPH}$.

In the SNP database (http://www.ncbi.nlm.nih.gov/SNP, BUILD 141), the C- and T-allele frequencies in the rs10993994 SNP have been reported to be 0.659 and 0.341 in Europeans, 0.593 and 0.407 in the Chinese, 0.587 and 0.413 in the Japanese, and 0.288 and 0.712 in Sub-Saharan Africans, respectively. In the control group recruited for this study, the $\mathrm{C}$ - and T-allele frequencies of rs10993994 were 0.846 and 0.154 , which are higher than those seen in other Asian populations. Moreover, the C-and T-allele frequencies of the rs102770171 SNP did not exist in SNP database. In this study, we first identified the Cand T-allele frequencies of the rs102770171 SNP. The C- and Tallele frequencies of rs 102770171 were 0.571 and 0.429 , respectively, in the Korean population.
To examine whether the rs12770171 SNP (-184C/T) influences transcription factors, we compared the transcription factor binding sites using the online program AliBaba 2.1 (http:// www.gene-regulation.com/pub/programs/alibaba2). At the rs12770171 SNP $(-184 \mathrm{C} / \mathrm{T})$ site, three transcription factors (Sp1) can bind to the C-containing sequence, but not to the Tcontaining sequence. This difference in transcription factor binding may influence MSMB expression.

To our knowledge, this is the first study to examine whether promoter SNPs (rs12770171, -184C/T and rs10993994, -2C/T) of the $M S M B$ gene are associated with development to $\mathrm{BPH}$ in a Korean population. We found that the promoter polymorphism (rs12770171, $-184 \mathrm{C} / \mathrm{T}$ ) of the MSMB gene is associated with BPH development. The T-allele frequency of the rs 12770174 SNP was higher in the BPH group than the control group. This result indicates that promoter polymorphism (rs12770171, $-184 \mathrm{C} / \mathrm{T}$ ) of the MSMB gene may contribute to BPH development in the Korean population. In future, additional studies with larger sample sizes or different populations will be needed to confirm our results.

\section{CONFLICT OF INTEREST}

No potential conflict of interest relevant to this article was reported.

\section{REFERENCES}

1. Kim SK, Kim YO, Lee BC, Yoo KH, Chung JH. Toll-like receptor 10-1-6 gene cluster polymorphisms are not associated with benign prostatic hyperplasia in Korean population. Int Neurourol J 2014; 18:10-5.

2. Hoke GP, McWilliams GW. Epidemiology of benign prostatic hyperplasia and comorbidities in racial and ethnic minority populations. Am J Med 2008;121(8 Suppl 2):S3-10.

3. Mikolajczyk SD, Song Y, Wong JR, Matson RS, Rittenhouse HG. Are multiple markers the future of prostate cancer diagnostics? Clin Biochem 2004;37:519-28.

4. Sanda MG, Beaty TH, Stutzman RE, Childs B, Walsh PC. Genetic susceptibility of benign prostatic hyperplasia. J Urol 1994;152:115-9.

5. Madigan MP, Gao YT, Deng J, Pfeiffer RM, Chang BL, Zheng S, et al. CYP17 polymorphisms in relation to risks of prostate cancer and benign prostatic hyperplasia: a population-based study in China. Int J Cancer 2003;107:271-5.

6. Novelli G, Margiotti K, Sangiuolo F, Reichardt JK. Pharmacogenet- 
ics of human androgens and prostatic diseases. Pharmacogenomics 2001;2:65-72.

7. Seok H, Yoo KH, Kim YO, Chung JH. Association of a missense ALDH2 single nucleotide polymorphism (Glu504Lys) with benign prostate hyperplasia in a Korean population. Int Neurourol J 2013; 17:168-73.

8. El Ezzi AA, Zaidan WR, El-Saidi MA, Al-Ahmadieh N, Mortenson JB, Kuddus RH. Association of benign prostate hyperplasia with polymorphisms in VDR, CYP17, and SRD5A2 genes among Lebanese men. Asian Pac J Cancer Prev 2014;15:1255-62.

9. Yoo KH, Kim SK, Chung JH, Chang SG. Nitric oxide synthase 2 gene polymorphisms are associated with prostatic volume in Korean men with benign prostatic hyperplasia. Asian J Androl 2010;12: 690-6.

10. Lilja $\mathrm{H}$, Abrahamsson PA. Three predominant proteins secreted by the human prostate gland. Prostate 1988;12:29-38.

11. Ulvsback M, Lindstrom C, Weiber H, Abrahamsson PA, Lilja $\mathrm{H}$, Lundwall A. Molecular cloning of a small prostate protein, known as beta-microsemenoprotein, PSP94 or beta-inhibin, and demonstration of transcripts in non-genital tissues. Biochem Biophys Res Commun 1989;164:1310-5.

12. Dube JY, Frenette G, Paquin R, Chapdelaine P, Tremblay J, Tremblay RR, et al. Isolation from human seminal plasma of an abundant 16-kDa protein originating from the prostate, its identification with a 94-residue peptide originally described as beta-inhibin. J Androl 1987;8:182-9.

13. Whitaker HC, Warren AY, Eeles R, Kote-Jarai Z, Neal DE. The potential value of microseminoprotein-beta as a prostate cancer biomarker and therapeutic target. Prostate 2010;70:333-40.

14. Garde SV, Basrur VS, Li L, Finkelman MA, Krishan A, Wellham L, et al. Prostate secretory protein (PSP94) suppresses the growth of androgen-independent prostate cancer cell line (PC3) and xenografts by inducing apoptosis. Prostate 1999;38:118-25.

15. Reeves JR, Dulude H, Panchal C, Daigneault L, Ramnani DM.
Prognostic value of prostate secretory protein of 94 amino acids and its binding protein after radical prostatectomy. Clin Cancer Res 2006;12(20 Pt 1):6018-22.

16. Chan PS, Chan LW, Xuan JW, Chin JL, Choi HL, Chan FL. In situ hybridization study of PSP94 (prostatic secretory protein of $94 \mathrm{ami}-$ no acids) expression in human prostates. Prostate 1999;41:99-109.

17. Gabriel SB, Schaffner SF, Nguyen H, Moore JM, Roy J, Blumenstiel $\mathrm{B}$, et al. The structure of haplotype blocks in the human genome. Science 2002;296:2225-9.

18. Sutcliffe S, De Marzo AM, Sfanos KS, Laurence M. MSMB variation and prostate cancer risk: clues towards a possible fungal etiology. Prostate 2014;74:569-78.

19. Lou H, Li H, Yeager M, Im K, Gold B, Schneider TD, et al. Promoter variants in the MSMB gene associated with prostate cancer regulate MSMB/NCOA4 fusion transcripts. Hum Genet 2012;131: 1453-66.

20. Pomerantz MM, Shrestha Y, Flavin RJ, Regan MM, Penney KL, Mucci LA, et al. Analysis of the 10q11 cancer risk locus implicates MSMB and NCOA4 in human prostate tumorigenesis. PLoS Genet 2010;6:e1001204.

21. Orsted DD, Bojesen SE. The link between benign prostatic hyperplasia and prostate cancer. Nat Rev Urol 2013;10:49-54.

22. Lou H, Yeager M, Li H, Bosquet JG, Hayes RB, Orr N, et al. Fine mapping and functional analysis of a common variant in MSMB on chromosome 10q11.2 associated with prostate cancer susceptibility. Proc Natl Acad Sci U S A 2009;106:7933-8.

23. Thomas G, Jacobs KB, Yeager M, Kraft P, Wacholder S, Orr N, et al. Multiple loci identified in a genome-wide association study of prostate cancer. Nat Genet 2008;40:310-5.

24. Nam RK, Reeves JR, Toi A, Dulude H, Trachtenberg J, Emami M, et al. A novel serum marker, total prostate secretory protein of 94 amino acids, improves prostate cancer detection and helps identify high grade cancers at diagnosis. J Urol 2006;175:1291-7. 